\title{
Magnetic and Electronic Structures of Cobalt or Copper Substituted $\mathrm{Mn}_{2} \mathrm{Sb}$
}

\author{
Junya Goto*, Takatoshi Kakimoto*, Shinpei Fujii and Keiichi Koyama \\ Graduate School of Science and Engineering, Kagoshima University, Kagoshima 890-0065, Japan
}

First-principles total-energy calculations have been performed for the hypothetical case of $x=1$ in $\mathrm{Mn}_{2-x} \mathrm{X}_{x} \mathrm{Sb}(\mathrm{X}=\mathrm{Co}$ and $\mathrm{Cu})$ for several magnetic states, using the full-potential linearized augmented plane wave method based on the generalized gradient approximation. The calculated total energy indicates that the $\mathrm{Co}(\mathrm{Cu})$ atom prefers the site $\mathrm{Mn}(\mathrm{I})$ to the site $\mathrm{Mn}(\mathrm{II})$ (Mn(II) to Mn(I)). This result of Co is consistent with the available neutron diffraction experiment. For CoMnSb where Co occupies the site $\mathrm{Mn}(\mathrm{I})$, the change of lattice constants $(a$ and $c)$ and $c / a$ from $\mathrm{AF} 2$ to $\mathrm{F}$ is in good agreement with experimental trends. Our results indicate that the optimization of the ratio $c / a$ (lattice distortion) is crucial to determine the most stable magnetic state and that the optimization of the atomic positions of the sites Mn(II) and Sb is also crucial. [doi:10.2320/matertrans.M2013327]

(Received August 26, 2013; Accepted September 30, 2013; Published November 9, 2013)

Keywords: cobalt or copper substitution, electronic and magnetic structures, first-principles calculations, Mn $n_{2} S b$

\section{Introduction}

The compound $\mathrm{Mn}_{2} \mathrm{Sb}$ with the tetragonal $\mathrm{Cu}_{2} \mathrm{Sb}$ structure $(P 4 / \mathrm{nmm})$ is ordered ferrimagnetically below $550 \mathrm{~K} .{ }^{1)}$ As shown in Fig. 1, it contains two crystallographically different $\mathrm{Mn}$ sites, i.e., $\mathrm{Mn}(\mathrm{I})$ and $\mathrm{Mn}(\mathrm{II})$, which are tetrahedrally and octahedrally surrounded by $\mathrm{Sb}$ atoms, respectively. The ferrimagnetic (FR) structure is formed by the antiparallel arrangement of the $\operatorname{Mn}(\mathrm{I})\left(2.13 \mu_{\mathrm{B}}\right)$ and $\mathrm{Mn}(\mathrm{II})\left(3.87 \mu_{\mathrm{B}}\right) .{ }^{1)}$

The substitution of $\mathrm{Co}$ or $\mathrm{Cu}$ for $\mathrm{Mn}$ results in the appearance of a first-order magnetic phase transition from FR to the antiferromagnetic (AF) state at $T_{\mathrm{t}}$ as temperature decreases. $^{2)}$ The FR to AF transition is accompanied with a large change in the volume, ${ }^{3-5)}$ resistivity, ${ }^{5,6)}$ magnetization, ${ }^{3-5)}$ etc. Application of magnetic field induces the first-order AF to FR transition, which is accompanied with large magnetoresistance, magnetostriction, etc. ${ }^{5,6)}$ Therefore, these compounds attract attention as a magnetic field controlled materials.

Recently, the phenomenon that a first-order phase transition is arrested by a magnetic field have been reported for magnetic materials, such as $\mathrm{Ce}\left(\mathrm{Fe}_{0.96} \mathrm{Al}_{0.04}\right)_{2}{ }^{7)} \mathrm{Ni}_{45} \mathrm{Co}_{5}-$ $\mathrm{Mn}_{36.7} \mathrm{In}_{13.3}{ }^{8}{ }^{8}$ This is so-called kinetic arrest (KA) effect. The KA effect is also reported for $\mathrm{Mn}_{1.85} \mathrm{Co}_{0.15} \mathrm{Sb}$, ${ }^{6}$ $\mathrm{Mn}_{1.8} \mathrm{Co}_{0.2} \mathrm{Sb},{ }^{5)} \mathrm{Mn}_{2-x} \mathrm{Cu}_{x} \mathrm{Sb} .{ }^{9)}$ It is very important to clarify the mechanism of the KA effect in the view of application of such magnetic field controlled materials.

In this paper, we investigate electronic and magnetic properties of $\mathrm{Mn}_{2-x} \mathrm{X}_{x} \mathrm{Sb}(\mathrm{X}=\mathrm{Co}$ and $\mathrm{Cu})$ by a first-principles band calculation to expand our knowledge for the materials.

\section{Approach}

First-principles total-energy calculations have been performed by the full-potential linearized augmented plane wave (FLAPW) method. ${ }^{10)}$ For the exchange-correlation energy or its corresponding potential, we used the generalized gradient approximation (GGA) by Perdew et al. (PBE96). ${ }^{11)}$ In the present study, the self-consistent calculation is performed using a $14 \times 14 \times 9 k$-point mesh. The plane-wave cutoff is $R K_{\max }=7.0$, where $R$ is the smallest atomic sphere

*Graduate Student, Kagoshima University
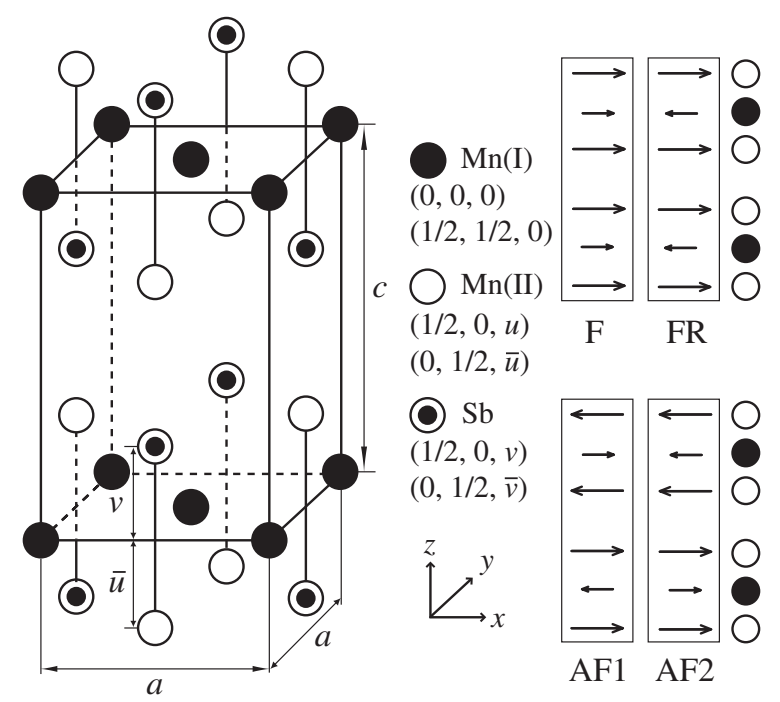

Fig. 1 Crystal structure of $\mathrm{Mn}_{2} \mathrm{Sb}$ and schematic representation of several magnetic structures.

radius and $K_{\max }$ is the magnitude of the largest $K$ vector. For the atomic-sphere radius, we used such values as 2.24 a.u. for $\mathrm{Mn}, \mathrm{Co}$ and $\mathrm{Cu}$, and 2.13 a.u. for $\mathrm{Sb}$. In the calculation of the equilibrium positions of the atoms in a cell, we used a reversed-communication trust-region QuasiNewton method. ${ }^{10)}$

In this paper, we have dealt with the hypothetical case of $x=1$ in $\mathrm{Mn}_{2-x} \mathrm{X}_{x} \mathrm{Sb}(\mathrm{X}=\mathrm{Co}$ and $\mathrm{Cu})$, that is, the $\mathrm{X}$ atom occupies the site $\mathrm{Mn}(\mathrm{I})$ (denoted by $\mathrm{XMnSb}$ ) or the site $\mathrm{Mn}(\mathrm{II})$ (MnXSb). For a magnetic phase, the following five structures shown in Fig. 1 are considered: ${ }^{12)}$ paramagnetic or non-magnetic $(\mathrm{P})$, ferromagnetic $(\mathrm{F})$, ferrimagnetic $(\mathrm{FR})$ and two antiferromagnetic (AF1, AF2) states. The FR and $\mathrm{AF} 1$ structures are equal to those reported for $\mathrm{Mn}_{2} \mathrm{Sb}^{1)}$ and $\mathrm{Mn}_{2} \mathrm{As},{ }^{13)}$ respectively.

For $\mathrm{CoMnSb}$ and $\mathrm{MnCoSb}$, we started the calculation with an antiparallel alignment of the spin magnetic moments on Co and Mn, but did not obtain a self-consistent solution. A solution with a parallel alignment of the spin magnetic moments on $\mathrm{Co}$ and $\mathrm{Mn}$ is only obtained. Thus, in $\mathrm{CoMnSb}$ and $\mathrm{MnCoSb}$, there exist only the F and AF2 states. 
(a)

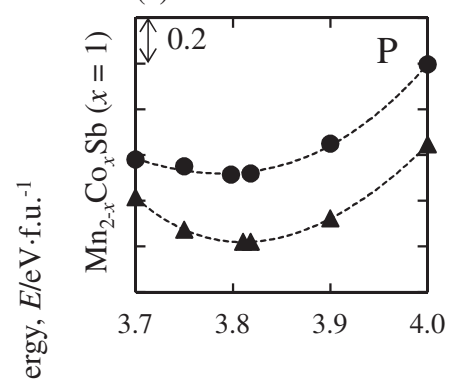

(d)

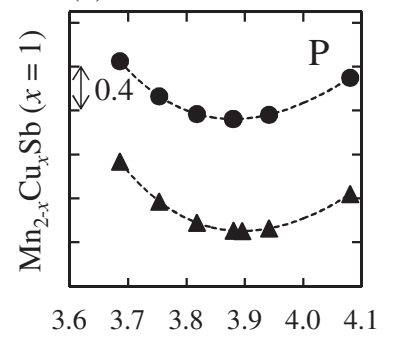

(b)

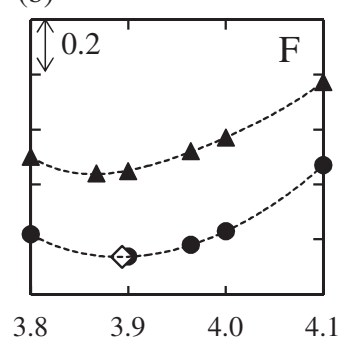

(e)

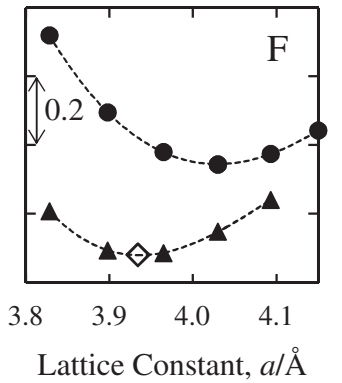

(c)

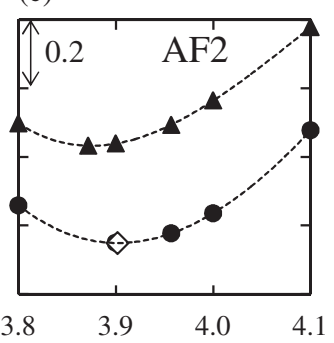

(f)

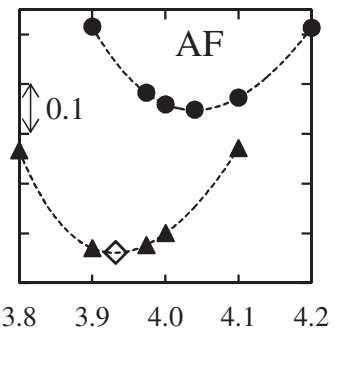

Fig. 2 Total energy vs lattice constant $a$. The upper panels (a), (b), (c) show the results of CoMnSb (O) and MnCoSb (A). The lower panels (d), (e), (f) show the results of $\mathrm{CuMnSb}(\boldsymbol{O})$ and $\mathrm{MnCuSb}(\boldsymbol{\Delta})$. The symbol $\diamond$ denotes the lattice constant that gives a minimum total energy.

\section{Results and Discussions}

\subsection{Site preference of $\mathrm{Co}$ and $\mathrm{Cu}$}

We have carried out total-energy calculations of hypothetical compounds for several magnetic states to gain insight in the site preference of $\mathrm{Co}$ and $\mathrm{Cu}$ atoms. The results of "energy vs $a$ " are shown in Fig. 2, where the following experimental values of $\mathrm{Mn}_{2} \mathrm{Sb}$ are used for the ratio $c / a$ and the atomic position parameters, $u$ and $v$ (see Fig. 1): $c / a=1.608, u=0.710, v=0.279 .{ }^{14)}$ Hereafter, we define " $V_{\mathrm{A}}$ " as the volume which gives the minimum energy in Fig. 2.

First we consider $\mathrm{CoMnSb}$ and $\mathrm{MnCoSb}$. The Fig. 2 shows that the total energy of $\mathrm{MnCoSb}(E(\mathrm{MnCoSb}))$ is lower than $E(\mathrm{CoMnSb})$ in the $\mathrm{P}$ state and that $E(\mathrm{CoMnSb})<E(\mathrm{MnCoSb})$ in $\mathrm{F}$ and $\mathrm{AF} 2$ states. This result indicates that the Co atom prefers the site $\mathrm{Mn}(\mathrm{I})$ to the site $\mathrm{Mn}(\mathrm{II})$ in a magnetic state. This is consistent with the report by Brown et al. ${ }^{15)}$ They showed that the Co atom occupies the site $\mathrm{Mn}(\mathrm{I})$ in $\mathrm{Mn}_{1.8} \mathrm{Co}_{0.2} \mathrm{Sb}$ from an analysis of the neutron diffraction experiment.

Second, we consider CuMnSb and MnCuSb. It is meaningless to distinguish $\mathrm{F}$ from FR (AF1 from AF2) because the magnetic moment on $\mathrm{Cu}$ is negligible (the value is less than $\left.0.01 \mu_{\mathrm{B}}\right)$. The Fig. 2 shows that $E(\mathrm{MnCuSb})<E(\mathrm{CuMnSb})$ in all magnetic states. This result indicates the $\mathrm{Cu}$ atom prefers the site $\mathrm{Mn}(\mathrm{II})$ to the site $\mathrm{Mn}(\mathrm{I})$. Unfortunately, we can not confirm our result because the information about the site preference of $\mathrm{Cu}$ is not available.

\subsection{Lattice deformation and atomic position}

Before we have a discussion about our present results, we make some comments on the predictability of our totalenergy calculation. (Concerning an accuracy of FLAPW method, see Ref. 16) for example.) We have obtained the result $^{17)}$ of $\Delta E=-0.06 \mathrm{eV} /$ f.u. $(+0.02 \mathrm{eV} /$ f.u. $)$ for $\mathrm{Mn}_{2} \mathrm{Sb}$ $\left(\mathrm{Mn}_{2} \mathrm{As}\right)$, where $\Delta E=E(\mathrm{FR})-E(\mathrm{AF} 1)$. Here $E(\mathrm{FR})$ and $E(\mathrm{AF} 1)$ means a total energy for the FR and AF1 states, respectively (see Fig. 1). Although the energy difference between FR and AF1 is small, these results are consistent with the experimental reports ${ }^{1,13}$ because the experimental observation shows that $\mathrm{Mn}_{2} \mathrm{Sb}\left(\mathrm{Mn}_{2} \mathrm{As}\right)$ has the FR (AF1) state for its magnetic ground state. Concerning a lattice constant, the discrepancy between our results and experimental ones ${ }^{14,18)}$ is lower than $3 \%$ for $\mathrm{Mn}_{2} \mathrm{Sb}$ and $\mathrm{Mn}_{2} \mathrm{As}$.

We show the result of a total energy as a function of $c / a$ in Figs. 3(a) and 3(b) for $\mathrm{CoMnSb}$ and $\mathrm{MnCuSb}$, respectively. In these figures, there are important three points $(\mathrm{A}, \mathrm{B}, \mathrm{C})$. At the point $\mathrm{A}$, the total energy is minimized as a function of $a$ (see Fig. 2). The points $\mathrm{B}$ and $\mathrm{C}$ show the ratio $c / a$ which gives minimum total energies before and after the optimization of atomic positions of $\mathrm{Mn}(\mathrm{II})$ and $\mathrm{Sb}$ for $\mathrm{CoMnSb}(\mathrm{Cu}$ and $\mathrm{Sb}$ for $\mathrm{MnCuSb})$ on the condition that $V=V_{\mathrm{A}}$, where " $V$ " means the unit-cell volume. The arrows in Fig. 3 show that the optimization of atomic positions at the point $\mathrm{B}$ decreases the total energy from the upper point to the lower point.

First we consider CoMnSb. At the point A, the total energy for the $\mathrm{F}$ state $(E(\mathrm{~F}))$ is lower than $E(\mathrm{AF} 2)$. However, $E(\mathrm{AF} 2)$ is lower than $E(\mathrm{~F})$ after the optimization of $c / a$. Moreover, the optimization of atomic positions of $\mathrm{Mn}(\mathrm{II})$ and $\mathrm{Sb}$ brings the result that $E(\mathrm{~F}) \approx E(\mathrm{AF} 2)$. These results indicate that the optimization of the lattice deformation and the atomic position is crucial in the determination of the stabilization of the two magnetic phases, F and AF2.

The result of $\mathrm{MnCuSb}$ is shown in Fig. 3(b). In this case, the relative stability of the two magnetic phases, $\mathrm{F}$ and $\mathrm{AF}$ is not changed by the optimization of the lattice deformation and the atomic position but the optimization of the atomic position leads to lower energy in both magnetic phases. 


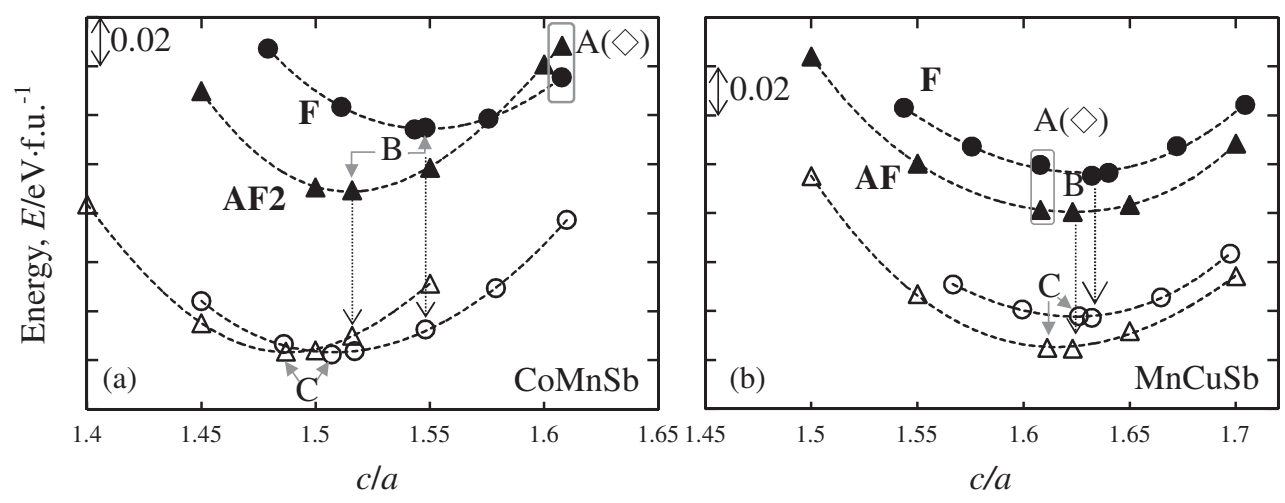

Fig. 3 Total energy vs $c / a$ for $\mathrm{F}$ and $\mathrm{AF} 2$ of CoMnSb (F and AF of MnCuSb). The symbols $\bigcirc$ and $\bigcirc(\Delta$ and $\triangle)$ mean the results for F (AF2) $(\mathrm{F}(\mathrm{AF}))$. The points $\mathrm{B}$ and $\mathrm{C}$ show the ratio $c / a$ which gives minimum energies before and after the optimization of atomic positions of $\mathrm{Mn}(\mathrm{II})$ and $\mathrm{Sb}$ for $\mathrm{CoMnSb}(\mathrm{Cu}$ and $\mathrm{Sb}$ for $\mathrm{MnCuSb})$. See text in detail.

Table 1 Volume of the unit cell $(V)$ and lattice constants $(a, c)$. The data are given at the points $\mathrm{B}$ and $\mathrm{C}$ in Fig. 3. The symbol $\Delta$ means $(\mathrm{F}-\mathrm{AF} 2) /$ $\mathrm{AF} 2 \times 100$ for $\mathrm{CoMnSb}$ and $(\mathrm{F}-\mathrm{AF}) / \mathrm{AF} \times 100$ for $\mathrm{MnCuSb}$. The lowest rows in $\mathrm{CoMnSb}$ and $\mathrm{MnCuSb}$ show the atomic position parameters, $u$ and $v$ (see Fig. 1).

\begin{tabular}{|c|c|c|c|c|c|c|}
\hline \multirow[t]{2}{*}{$\mathrm{CoMnSb}$} & \multicolumn{3}{|c|}{ B } & \multicolumn{3}{|c|}{$\mathrm{C}$} \\
\hline & $\mathrm{F}$ & AF2 & $\Delta(\%)$ & $\mathrm{F}$ & AF2 & $\Delta(\%)$ \\
\hline$V\left(\AA^{3}\right)$ & 94.903 & 95.496 & -0.621 & 94.903 & 95.496 & -0.621 \\
\hline$a(\AA)$ & 3.943 & 3.979 & -0.900 & 3.979 & 4.005 & -0.651 \\
\hline$c(\AA)$ & 6.104 & 6.032 & +1.192 & 5.996 & 5.955 & +0.685 \\
\hline$c / a$ & 1.548 & 1.516 & +2.111 & 1.507 & 1.487 & +1.345 \\
\hline$u$ & \multicolumn{2}{|c|}{0.710} & & 0.738 & 0.730 & \\
\hline$v$ & \multicolumn{2}{|c|}{0.279} & & 0.284 & 0.278 & \\
\hline $\mathrm{MnCuSb}$ & \multicolumn{3}{|c|}{ B } & \multicolumn{3}{|c|}{$\mathrm{C}$} \\
\hline & $\mathrm{F}$ & $\mathrm{AF}$ & $\Delta(\%)$ & $\mathrm{F}$ & $\mathrm{AF}$ & $\Delta(\%)$ \\
\hline$V\left(\AA^{3}\right)$ & 97.897 & 97.749 & +0.151 & 97.897 & 97.749 & +0.151 \\
\hline$a(\AA)$ & 3.915 & 3.920 & -0.134 & 3.919 & 3.930 & -0.258 \\
\hline$c(\AA)$ & 6.389 & 6.362 & +0.420 & 6.373 & 6.330 & +0.671 \\
\hline$c / a$ & 1.632 & 1.623 & +0.555 & 1.626 & 1.611 & +0.931 \\
\hline$u$ & \multicolumn{2}{|c|}{0.710} & & 0.722 & 0.722 & \\
\hline$v$ & \multicolumn{2}{|c|}{0.279} & & 0.298 & 0.296 & \\
\hline
\end{tabular}

In Table 1 we summarize the data such as the volume of the unit cell and lattice constants at the points $\mathrm{B}$ and $\mathrm{C}$ in Figs. 3(a) and 3(b). The atomic position parameters, $u$ and $v$ (see Fig. 1) are also listed in Table 1. In both of $\mathrm{CoMnSb}$ and $\mathrm{MnCuSb}$, the change from AF2 (AF) to $\mathrm{F}$ at the point $\mathrm{B}$ is similar to that at the point $\mathrm{C}$. The difference between $\mathrm{CoMnSb}$ and $\mathrm{MnCuSb}$ appears in the change of the volume of the unit cell $(V$ ) from AF2 (AF) to F, that is, the $V$ shrinks from $\mathrm{AF} 2$ to $\mathrm{F}$ in $\mathrm{CoMnSb}$ but it expands from $\mathrm{AF}$ to $\mathrm{F}$ in $\mathrm{MnCuSb}$. The change of lattice constants $(a$ and $c$ ) and $c / a$ is consistent with the experimental result for $\mathrm{Mn}_{1.8} \mathrm{Co}_{0.2} \mathrm{Sb}^{3}$ )

The calculated data for the magnetic moment of each atom in $\mathrm{CoMnSb}$ and $\mathrm{MnCuSb}$ are listed in Table 2, together with experimental data in $\mathrm{Mn}_{2} \mathrm{Sb}$ and $\mathrm{Mn}_{1.9} \mathrm{Co}_{0.1} \mathrm{Sb}$. Our previous calculated data in $\mathrm{Mn}_{2} \mathrm{Sb}$ are shown in parentheses. (The absolute value of the magnetic moment on $\mathrm{Sb}$ is less than $0.06 \mu_{\mathrm{B}}$.) This table shows that the values of the magnetic moments of constituent atoms barely change from the point $\mathrm{B}$ to the point $\mathrm{C}$ except for the $\mathrm{AF}$ state in $\mathrm{MnCuSb}$,
Table 2 Calculated magnetic moments on constituent atoms in CoMnSb and $\mathrm{MnCuSb}$. The experimental data in $\mathrm{Mn}_{2} \mathrm{Sb}$ and $\mathrm{Mn}_{1.9} \mathrm{Co}_{0.1} \mathrm{Sb}$ are also listed. Our calculate data for $\mathrm{Mn}_{2} \mathrm{Sb}$ are shown in parentheses.

\begin{tabular}{|c|c|c|c|c|}
\hline \multicolumn{5}{|c|}{ Magnetic moment, $m / \mu_{\mathrm{B}}$} \\
\hline \multicolumn{5}{|c|}{$\mathrm{CoMnSb}$} \\
\hline site & $\mathrm{F}(\mathrm{B})$ & AF2 (B) & $\mathrm{F}(\mathrm{C})$ & $\mathrm{AF} 2(\mathrm{C})$ \\
\hline $\mathrm{Co}$ & 0.85 & 1.00 & 1.08 & 1.08 \\
\hline $\operatorname{Mn}(\mathrm{II})$ & 3.35 & 3.41 & 3.35 & 3.41 \\
\hline \multicolumn{5}{|c|}{$\mathrm{MnCuSb}$} \\
\hline site & $\mathrm{F}(\mathrm{B})$ & $\mathrm{AF}(\mathrm{B})$ & $\mathrm{F}(\mathrm{C})$ & $\mathrm{AF}(\mathrm{C})$ \\
\hline $\mathrm{Mn}(\mathrm{I})$ & -2.25 & -2.17 & -2.39 & -2.33 \\
\hline & \multicolumn{2}{|c|}{$\mathrm{Mn}_{2} \mathrm{Sb}$} & \multicolumn{2}{|c|}{$\mathrm{Mn}_{1.9} \mathrm{Co}_{0.1} \mathrm{Sb}$} \\
\hline site & $\mathrm{FR}^{1)}$ & $\mathrm{FR}^{17)}$ & \multicolumn{2}{|c|}{$\mathrm{AF} 1^{15)}$} \\
\hline $\operatorname{Mn}(\mathrm{I})$ & -2.13 & $(-2.17)$ & \multicolumn{2}{|c|}{-1.71} \\
\hline $\mathrm{Mn}(\mathrm{II})$ & 3.87 & (3.39) & \multicolumn{2}{|c|}{3.98} \\
\hline
\end{tabular}

that is, the values of the magnetic moments are not sensitive to the optimization of the atomic positions of $\mathrm{Mn}(\mathrm{II})$ and $\mathrm{Sb}$.

The result that $\mathrm{CoMnSb}$ has the same magnetic moment on $\mathrm{Mn}(\mathrm{II}), 3.4 \mu_{\mathrm{B}}$, as $\mathrm{Mn}_{2} \mathrm{Sb}$ indicates that the magnetic moment on $\mathrm{Mn}$ (II) is not sensitive to the substitution of Co for $\mathrm{Mn}(\mathrm{I})$. This is consistent with experimental report. ${ }^{15)} \mathrm{Mn}_{1.9} \mathrm{Co}_{0.1} \mathrm{Sb}$ has the almost same magnetic moment on $\mathrm{Mn}(\mathrm{II}), 3.98 \mu_{\mathrm{B}}$, as $\mathrm{Mn}_{2} \mathrm{Sb}\left(3.87 \mu_{\mathrm{B}}\right)$, irrespective of the fact that the magnetic moment on $\mathrm{Mn}(\mathrm{I})$ changes from $-2.13 \mu_{\mathrm{B}}$ on $\mathrm{Mn}(\mathrm{I})$ in $\mathrm{Mn}_{2} \mathrm{Sb}$ to $-1.71 \mu_{\mathrm{B}}$ in $\mathrm{Mn}_{1.9} \mathrm{Co}_{0.1} \mathrm{Sb}$.

If we estimate the magnetic moment on $\mathrm{Mn}(\mathrm{I})$ in $\mathrm{Mn}_{1.9} \mathrm{Co}_{0.1} \mathrm{Sb}$ from the data of $\mathrm{CoMnSb}$, then we obtain the value of $-1.8 \mu_{\mathrm{B}}$. This is very close to the experimental one, $-1.71 \mu_{\mathrm{B}}$. This result indicates the Co atom occupies the site $\mathrm{Mn}(\mathrm{I})$ with magnetic moment $1 \mu_{\mathrm{B}}$.

For $\mathrm{Mn}_{1.82} \mathrm{Co}_{0.18} \mathrm{Sb}$, it is reported that the electronic specific heat coefficient $\gamma$ increases by $\approx 39 \%$ at the critical field for the filed induced AF-FR transition due to an increase in the density of states (DOS) at the Fermi energy. ${ }^{4,15)}$ Thus, we estimate DOS at the Fermi energy and $\gamma$ for CoMnSb and $\mathrm{MnCuSb}$, and shows results in Table 3. Here the $\gamma$ can be derived from $D\left(E_{\mathrm{F}}\right)$ using $\gamma=(1 / 3) \pi^{2} D\left(E_{\mathrm{F}}\right) k_{\mathrm{B}}^{2}$ where $k_{\mathrm{B}}$ is the Boltzmann constant. This table shows that in both of $\mathrm{CoMnSb}$ and $\mathrm{MnCuSb}$ the DOS increases from AF2 (AF) to 
Table 3 Density of states at the Fermi energy and electronic specific heat coefficient. The data are estimated at the points $\mathrm{B}$ and $\mathrm{C}$ in Fig. 3. The symbol $\Delta$ means $(\mathrm{F}-\mathrm{AF} 2) / \mathrm{AF} 2 \times 100$ for $\mathrm{CoMnSb}$ and $(\mathrm{F}-\mathrm{AF}) /$ $\mathrm{AF} \times 100$ for $\mathrm{MnCuSb}$.

\begin{tabular}{|c|c|c|c|c|c|}
\hline \multicolumn{6}{|c|}{$\begin{array}{l}D O S, D / \text { states } \cdot \mathrm{eV}^{-1} \cdot \mathrm{f} . \mathrm{u} \cdot{ }^{-1} \cdot \mathrm{spin}^{-1} \\
\text { (Electronic specific heat coefficient, } \gamma / \mathrm{mJ}^{-} \mathrm{mol}^{-1} \cdot \mathrm{K}^{-2} \text { ) }\end{array}$} \\
\hline \multicolumn{3}{|c|}{$\mathrm{CoMnSb}$} & \multicolumn{3}{|c|}{$\mathrm{MnCuSb}$} \\
\hline & B & $\mathrm{C}$ & & B & $\mathrm{C}$ \\
\hline $\mathrm{F}$ & $1.52(7.17)$ & $1.04(4.90)$ & $\mathrm{F}$ & $0.99(4.66)$ & 0.88 (4.16) \\
\hline AF2 & $1.08(5.08)$ & $1.03(4.87)$ & $\mathrm{AF}$ & $0.69(3.24)$ & $0.82(3.87)$ \\
\hline$\Delta(\%)$ & 41 & 0.5 & $\Delta(\%)$ & 44 & 7.3 \\
\hline
\end{tabular}

$\mathrm{F}$ at the point $\mathrm{B}$ but the enhancement almost disappears at the point $C$. The experimental estimation of $\Delta \approx 39 \%$ for $\mathrm{Mn}_{1.82} \mathrm{Co}_{0.18} \mathrm{Sb}^{4,15)}$ is very close to $\Delta=41 \%$ for $\mathrm{CoMnSb}$ at the point $\mathrm{B}$ (not at the point $\mathrm{C}$ ). Further investigation is needed to clarify this point.

\section{Conclusion}

First-principles band-structure calculations have been carried out the hypothetical case of $x=1$ in $\mathrm{Mn}_{2-x} \mathrm{X}_{x} \mathrm{Sb}$ $(\mathrm{X}=\mathrm{Co}$ and $\mathrm{Cu})$ for several magnetic states. The calculated total energy indicates that the Co atom prefers the site $\mathrm{Mn}(\mathrm{I})$ to the site $\mathrm{Mn}(\mathrm{II})$ in a magnetic state. This is consistent with the neutron diffraction experiment. ${ }^{15)}$ In the case of $\mathrm{Cu}$, the $\mathrm{Cu}$ atom prefers the site $\mathrm{Mn}(\mathrm{II})$ to the site $\mathrm{Mn}(\mathrm{I})$ in all magnetic states. To confirm this calculated result, we hope for neutron diffraction measurements on $\mathrm{Cu}$ substituted $\mathrm{Mn}_{2} \mathrm{Sb}$.

For CoMnSb, the change of lattice constants ( $a$ and $c$ ) and $c / a$ from AF2 to $\mathrm{F}$ is in good agreement with experimental trends. ${ }^{3)}$ Further, the magnetic moment on $\mathrm{Mn}(\mathrm{I})$ in $\mathrm{Mn}_{1.9} \mathrm{Co}_{0.1} \mathrm{Sb}$ estimated from our data of $\mathrm{CoMnSb}$ is very close to the experimental one. ${ }^{15)}$

Our results indicate that the optimization of the ratio $c / a$ is crucial to determine the most stable magnetic state and that the optimization of the atomic positions of the sites $\mathrm{Mn}$ (II) and $\mathrm{Sb}$ is also crucial.

In this study, we have only dealt with the case of $x=1$. In order to compare with the experimental results such as $\mathrm{Mn}_{1.8} \mathrm{Co}_{0.2} \mathrm{Sb},{ }^{5)} \mathrm{Mn}_{1.9} \mathrm{Cu}_{0.1} \mathrm{Sb}^{9,19)}$ etc., it is necessary to deal with the case of a low amount of substitution of $\mathrm{Co}$ or $\mathrm{Cu}$. First-principles calculations for this purpose are in progress.

\section{Acknowledgments}

This work was supported by JSPS KAKENHI Grant Number 24560855.

\section{REFERENCES}

1) M. K. Wilkinson, N. S. Gingrich and C. G. Shull: J. Phys. Chem. Solids 2 (1957) 289-300.

2) T. A. Bither, P. H. L. Walter, W. H. Cloud, T. J. Swoboda and P. E. Bierstedt: J. Appl. Phys. 33 (1962) 1346-1347.

3) M. I. Bartashevich, T. Goto, N. V. Baranov and V. S. Gaviko: Phys. B 351 (2004) 71-76.

4) M. I. Bartashevich, T. Goto, T. Tomita, N. V. Baranov, S. V. Zemlyanski, G. Hilscher and H. Michor: Phys. B 318 (2002) 198-210.

5) H. Orihashi, D. Mitsunaga, M. Hiroi, Y. Mitsui, K. Takahashi, K. Watanabe and K. Koyama: J. Japan Inst. Metals 76 (2012) 246-250.

6) P. Kushwaha, R. Rawat and P. Chaddah: J. Phys. Condens. Matter 20 (2008) 022204.

7) M. A. Manekar, S. Chaudhary, M. K. Chattopadhyay, K. J. Singh, S. B. Roy and P. Chaddah: Phys. Rev. B 64 (2001) 104416.

8) W. Ito, K. Ito, R. Y. Umetsu, R. Kainuma, K. Koyama, K. Watanabe, A. Fujita, K. Oikawa, K. Ishida and T. Kanomata: Appl. Phys. Lett. 92 (2008) 021908.

9) Y. Matsumoto, H. Orihashi, K. Matsubayashi, Y. Uwatoko, M. Hiroi and K. Koyama: IEEE Trans. Magn. to be published.

10) P. Blaha, K. Schwarz, G. K. H. Madsen, D. Kvasnicka and J. Luitz: WIEN2k, An Augmented Plane Wave + Local Orbitals Program for Calculating Crystal Properties (Karlheinz Schwarz, Techn. Universität Wien, Austria), 2001.

11) J. P. Perdew, K. Burke and M. Ernzerhof: Phys. Rev. Lett. 77 (1996) 3865-3868.

12) K. Shirakawa and H. Ido: J. Phys. Soc. Jpn. 40 (1976) 666-673.

13) A. E. Austin, E. Adelson and W. H. Cloud: J. Appl. Phys. 33 (1962) 1356-1357.

14) H. A. Alperin, P. J. Brown and R. Nathans: J. Appl. Phys. 34 (1963) 1201-1202.

15) P. J. Brown, A. P. Gandy, T. Kanomata and K. R. A. Ziebeck: J. Phys. Condens. Matter 20 (2008) 015220.

16) H. J. F. Jansen, K. B. Hathaway and A. J. Freeman: Phys. Rev. B 30 (1984) 6177-6179.

17) T. Kakimoto, S. Fujii and K. Koyama: Collected Abstracts of the 2012 Autumn Meeting of the Japan Inst. Metals, (2012) No. P66 (DVD).

18) H. Nowotny and F. Halla: Z. Phys. Chem. B 36 (1937) 322.

19) Y. Q. Zhang, Z. D. Zhang, D. K. Xiong, W. F. Li and J. He: J. Appl. Phys. 94 (2003) 4726-4728. 